\title{
Condições de trabalho e saúde de professores do ensino superior no oeste catarinense
}

\author{
Working conditions and health of teachers in \\ higher education in western Santa Catarina
}

FisiSenectus . Unochapecó Ano 1 - Edição especial - 2013 p. 85-95

\section{Cláudia Nesi Rezer}

Fisioterapeuta pela Unochapecó. claunesi@unochapeco.edu.br

\section{Mara Fernanda Donat}

Fisioterapeuta pela Unochapecó. mara.adm@unochapeco.edu.br

\section{Fátima Ferretti}

Professora do Programa de Mestrado em Ciências da Saúde da Unochapecó. ferrettifisio@ unochapeco.edu.br

\section{Cássia Cristina Braghini}

Mestranda em Ciências da Saúde pela Unochapecó. cafisio@unochapeco.edu.br

\section{Resumo}

Introdução: Os estudos das condições de saúde e trabalho de grupos ocupacionais permitem caracterizar os processos laborativos e construir um perfil para compreender as interações entre trabalho e a saúde/doença. 0 número de professores universitários aumentou em função da expansão do ensino superior e são poucas as publicações sobre a situação de saúde destes, o que demanda uma atenção especial. Objetivos: Analisar as condições de saúde e trabalho dos professores universitários numa instituição de ensino superior (IES) comunitária no estado de Santa Catarina e identificar a interferência do trabalho no dia a dia dos professores. Métodos: A pesquisa é do tipo quantitativo e descritivo com amostra composta por 87 professores. Os instrumentos de coleta de dados utilizados foram o questionário adaptado de Matos (2003) e Taube (2002) e o item short form health survey do medical outcomes study - 36. Resultados: A média geral de idade foi de $43( \pm 7,9)$ anos, 93,10\% eram doutores ou mestres, com média de $12,35( \pm 6,48)$ anos na função de professor e $10,86( \pm 5,60)$ anos de atuação na ies, realizando uma média de $6,85( \pm 2,66)$ horas diárias. Destes, $50,57 \%$ afirmaram realizar horas extras. A rotina de trabalho interferia no desempenho mental de $26,67 \%$ da amostra e desempenho físico em 28,33\%; já 70\% relataram ter sentido dor nas últimas quatro semanas e 83,91\% afirmaram que as condições de saúde interferiram no seu trabalho. Conclusão: Os professores estão constantemente expostos a fatores de risco como a dor, realização de horas extras, sobrecarga mental e física e desestimulo pela função, o que pode gerar vários transtornos físicos e psíquicos.

\section{Palavras-chave}

Saúde. Trabalho. Professor. Ensino superior. 


\begin{abstract}
Introduction: The study of health and occupational work groups can characterize the processes laborativos and build a profile to understand the interactions between work and health / disease. The number of faculty has increased due to the expansion of higher education and there are few publications on the health status of these, which demand special attention. Objective: To analyze the health and work of academics in an institution of higher learning in the state of Santa Catarina. Methods: The research is quantitative and descriptive sample of 87 teachers. The data collection instruments used were a questionnaire adapted from Matos (2003) and Taube (2002) and item short form health survey of the medical outcomes study-36. Results: The overall mean age was $43( \pm 7.9)$ years, $93.10 \%$ were doctors or teachers, with an average of $12.35( \pm 6.48)$ years as a teacher and $10.86( \pm 5.60)$ years of experience in the IES, performing an average of $6.85( \pm 2.66)$ hours per day. Of these, $50.57 \%$ reported receiving overtime. The work schedule interfered with the mental performance of $26.67 \%$ of the sample and physical performance of $28.33 \%$, whereas $70 \%$ reported having experienced pain in the last four weeks and $83.91 \%$ said that health conditions interfered in their work. Conclusion: Teachers are constantly exposed to risk factors such as pain, performing overtime, and physical and mental overload disincentive for function, which can generate various physical and mental disorders.
\end{abstract}

\title{
Keywords
}

Health. Work. Teacher. Higher Education.

\section{Introdução}

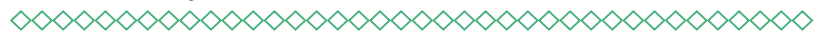

Para Silva ${ }^{1}$, o trabalho configura-se como uma atividade coordenada, de caráter físico e intelectual que visa alcançar um determinado objetivo. A relação entre o trabalho e a saúde/doença passou a ser mais abordada a partir da Revolução Industrial, momento em que os trabalhadores passaram a vender sua mão de obra de forma barata, tendo que se adaptar ao processo produtivo, à acumulação rápida de capital e ao aproveitamento dos equipamentos ${ }^{2}$.

A organização do trabalho interfere na vida do trabalhador, assim como o tempo que ele passa no ambiente de trabalho. Quanto maior a jornada, menor é o tempo disponível para o convívio familiar, assim como o cansaço que pode interferir no relacionamento do trabalhador com seus familiares ${ }^{3}$.

Atualmente, tem-se destacado a influência do trabalho no processo de saúde e doença. Dependendo da profissão exercida, existem determinantes na execução da atividade laboral que podem agravar as condições de saúde do indivíduo, levando-o a um quadro patológico, à fadiga física ou a exaustão mental. A forma como o processo de trabalho é organizado, o cotidiano no local de trabalho, os processos no qual o modo de trabalhar, de se relacionar, de lidar com o tempo, o espaço e os equipamentos pode ser danoso à saúde ${ }^{4}$.
A organização do trabalho interfere na vida de qualquer trabalhador, assim como o tempo que ele passa no ambiente de trabalho; pois quanto maior a jornada menor será o tempo possível para o convívio familiar, e quanto maior o cansaço mais difícil será o relacionamento do trabalhador com seus familiares ${ }^{3}$.

No caso do professor, o processo de trabalho se dá pela construção de conhecimento e aprendizagem que não podem ser analisados de forma isolada das relações interpessoais que ocorrem na estrutura social e na contemporaneidade ${ }^{5}$.

Atualmente, o papel do professor ampliou-se para além de mediador do processo de conhecimento de seu aluno. Seu trabalho vai além da sala de aula, ele deve participar da gestão e do planejamento da instituição de ensino, o que representa uma maior dedicação ao trabalho. Nesse contexto, a atividade laboral perpassa o espaço do lar e, muitas vezes, as horas de convívio, lazer e descanso podem ser absorvidas por atividades extraclasses, fator que ao longo dos anos pode provocar enfermidades psíquicas ou físicas ${ }^{6}$.

Vários são os fatores que podem influenciar o trabalho do professor no seu dia a dia, entre eles as condições climáticas do ambiente, mobiliário, estrutura física, carga horária, tipo de atividade, relacionamento interpessoal, se a atividade é prazerosa ou não, sobrecarga de trabalho, entre outras. 
A situação da saúde dos professores universitários demanda atenção especial, pois é uma profissão que tem o número de trabalhadores aumentando nas últimas décadas, com o crescente número de instituições de ensino e, caso os problemas elencados não sejam investigados e sanados, teremos em sala de aula um profissional desmotivado, enfermo, em esgotamento tanto físico quanto psíquico.

A produção científica nessa área apresenta uma tendência de crescimento nas últimas décadas, recebendo contribuições de diversos campos do saber. Isso se deve ao crescimento das IES por todo Brasil e o surgimento de problemas vinculados a função de professor universitário ${ }^{7}$.

No entanto, a literatura sobre condições de trabalho e saúde de docentes, principalmente no nível universitário, quando comparada a outras áreas trabalhistas, ainda é escassa. Muitos estudos publicados evidenciam as relações entre saúde e trabalho, em contextos fabris, em que a relação entre trabalho e saúde é mais direta e os riscos à saúde são mais evidentes. Portanto, pesquisas sobre condições de saúde e sua relação com o trabalho do professor universitário são importantes para planejar ações a fim de melhorar a saúde desse grupo populacional ${ }^{8}$.

Desse modo, deve-se conhecer o exercício das atividades desenvolvidas pelos professores, a estrutura e a organização do trabalho e se esses fatores interferem no desenvolvimento da atividade laborativa o que, consequentemente, poderá impactar na qualidade do ensino oferecido, no processo ensino-aprendizagem, na educação dos alunos e na saúde dos professores.

Diante do contexto exposto, os objetivos deste estudo foram analisar as condições de saúde e trabalho dos professores universitários em uma Instituição de Ensino Superior (IES) comunitária no estado de Santa Catarina e identificar a interferência do trabalho no dia a dia dos professores.

\section{Materiais e métodos}

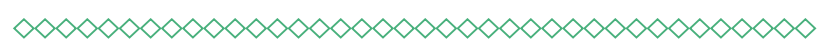

Esse estudo se caracteriza como quantitativo, descritivo e observacional. A população foi composta pelos professores universitários em exer- cício em uma Universidade Comunitária do oeste catarinense, que possuía 160 professores com contrato efetivo de 20 a 40 horas, nas áreas de Ciências da Saúde, Humanas e Jurídicas, Sociais Aplicadas e Exatas e Ambientais.

A amostra foi composta observando-se intervalo de confiança de $99 \%$ e margem de erro de $1 \%$ calculada através do programa PEPI 4.0 (DOS), totalizando 87 docentes. Foram incluídos os professores em atividade na universidade há mais de dois anos, com carga horária de 20 a 40 horas. Constituíram os critérios de exclusão os profissionais que estavam em férias no período da coleta de dados ou em afastamento por motivo de doença.

0 instrumento de coleta de dados foi o questionário adaptado de Matos $^{9}$ e Taube ${ }^{10}$ para identificação das condições de trabalho dos professores, contendo questões abertas e fechadas. Para a verificação das condições de saúde foi utilizado o questionário Medical Outcomes Study - 36 Item short form health survey - SF 36, avaliando as seguintes variáveis: capacidade funcional, aspectos físicos, dor, estado geral da saúde, aspectos sociais, aspectos emocionais e saúde mental. Os instrumentos foram autoaplicados nos meses de fevereiro e março de 2010.

Os dados foram categorizados e analisados por meio do programa SPSS versão 20.0. Foi realizada análise inferencial com percentual e desvio padrão. 0 projeto de pesquisa foi submetido ao Comitê de Ética e Pesquisa da universidade, aprovado sob protocolo $n^{\circ} 278 / 09$.

\section{Resultados}

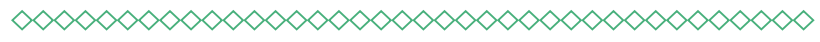

A amostra do estudo foi composta por 87 professores universitários registrados com 20 horas ou mais na função e há mais de dois anos na Instituição. A tabela 1 apresenta o perfil destes professores. Quanto ao gênero 48,28\% eram homens e $51,72 \%$ mulheres. A faixa etária predominante foi dos 41 aos 46 anos, com 26,44\%, seguida de 47 a 52 anos, com 25,29\%, e 35 a 40 anos, com 20,69\%. A média geral de idade foi de $43( \pm 7,9)$ anos, e a média entre as mulheres foi de $42( \pm 7,36)$ anos e entre os homens de $43( \pm 8,44)$ anos. Com relação à 
titulação, 6,90\% eram especialistas, 75,86\% mestres e $17,24 \%$ doutores.

A tabela 2 descreve as características vinculadas ao trabalho dos professores universitários. Quanto ao tempo de profissão a média foi de 12,35 $( \pm 6,4)$ anos, sendo o tempo mínimo de 4 anos e 0 máximo de 37 anos de atuação. A maioria, 32,18\%, tinha de 9 a 13 anos de atuação. Quanto ao tempo de trabalho na IES a média foi de $10,8( \pm 5,6)$ anos, sendo o mínimo apresentado de 2 anos e 0 máximo de 29 anos. A média diária de trabalho foi de 6,8 horas $( \pm 2,66)$, sendo que $41,38 \%$ faziam de 7 a 8 horas dia e $44,83 \%$ relataram trabalhar nos turnos matutino/vespertino/noturno. Em relação às horas extras, 50,57\% afirmaram fazer horas extras e a média de horas extras relatada foi de 33 $( \pm 21,89)$.

A tabela 3 apresenta dados quanto aos aspectos físicos inadequados da sala de aula, e destes o calor foi destaque em $31,51 \%$ das respostas, os ruídos externos em $23,29 \%$ e ventilação em 10,27\%. Quanto ao aspecto que os desestimulavam, foi verificado que $28,43 \%$ relataram carga horária de trabalho elevada, $17,65 \%$ colocaram a indisciplina dos acadêmicos, $21,57 \%$ a desvalorização profissional e 7,84\% a baixa remuneração.

A tabela 4 destaca os dados quanto à percepção da saúde e presença de dor em professores. Quanto à percepção de saúde, 58,62\% relataram que a sua saúde em geral em comparação a um ano atrás permaneceu quase a mesma e $20,69 \%$ afirmaram que ela se encontrava um pouco pior que um ano atrás. Quando questionados em relação à quantidade de dor que tiveram nas últimas quatro semanas, 29,90\% relataram que não tiveram dor no corpo e $28,70 \%$ afirmaram sentir dores leves. Quanto à interferência da dor no trabalho, 34,50\% relataram que interferiu um pouco; $33,30 \%$ de maneira alguma; $26,40 \%$ moderadamente; $4,60 \%$ relataram que a dor interferiu bastante e apenas $1,10 \%$ consideraram que a dor interferiu extremamente.

Em relação à interferência do trabalho no dia a dia (tabela 5), 26,67\% dos professores responderam que o desempenho mental foi afetado pela rotina de trabalho, 28,33\% relataram comprometimento do desempenho físico, $11,67 \%$ no relacionamento com os filhos. Já quanto à interferência da condição de saúde física e emocional no trabalho, 32,18\% relataram que estas variáveis interferiram bastante na realização do trabalho; $26,44 \%$ relataram que interferiu moderadamente; $25,29 \%$ ligeiramente; $10,34 \%$ de maneira alguma e $5,75 \%$ extremamente.

\section{Discussão}

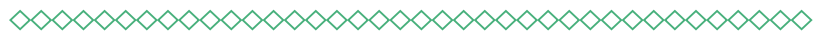

Diante dos dados coletados, observou-se que o perfil da amostra foi homogêneo, tendo um percentual aproximado de homens (48,28\%) e de mulheres (51,72\%) atuando nesta IES. Em estudo realizado com professores da Universidade Federal do Mato Grosso do Sul, o maior percentual de professores foi do sexo masculino $(61,5 \%)$, o que para os autores reflete uma realidade em que no nível superior de ensino os homens representam a maioria, ao contrário de outros níveis como ensino básico ou em séries iniciais em que o gênero feminino predomina, ou seja, quanto maior o prestígio social e status no trabalho como docente e/ou pesquisador, maior relação com o gênero masculino ${ }^{11}$.

Por outro lado, outros pesquisadores ${ }^{8}$ encontraram 39,5\% do gênero masculino e 52,9\% do gênero feminino atuando na Universidade Estadual de Feira de Santana (BA). Para eles, a predominância do gênero feminino entre os profissionais da educação está relacionada à inserção da mulher no mercado de trabalho, sendo que com a expansão do setor educacional no Brasil, a partir da segunda metade do século XX, as mulheres passaram a ocupar os cargos de educadores.

A média de idade foi de 43 anos e a faixa etária prevalente foi de 35 a 50 anos. Quanto a titulação $75,86 \%$ eram mestres e $17,24 \%$ doutores, demonstrando que a busca pela qualificação tem sido constante na vida destes professores, pois é uma exigência do mercado de trabalho. Araújo et $a .^{8}{ }^{8}$ descreveram as características do trabalho docente e as queixas de saúde de professores universitários de Feira de Santana (BA) e também encontraram o predomínio de professores com idade entre 30 a 49 anos com titulação de mestres e/ ou doutores. A faixa etária entre os 30 e 50 anos representa, para a maior parte dos estudantes, 0 período em que é possível alcançar níveis maiores de titulação. 
A maioria dos professores deste estudo tinha entre 4 e 13 anos de atuação na IES (62,07\%), realidade diferente foi apresentada em uma Universidade pública da Bahia na qual a maior parte (35,5\%) dos professores tinham entre 16 e 25 anos de atuação, com 20 a 40 horas semanais. Esse fato pode ser explicado em função de que a IES estudada passou por processo de reestruturação para Universidade Comunitária recentemente, diferente dos casos de Universidades Federais.

Cerca de $41,38 \%$ dos professores trabalhavam de 7 a 8 horas diárias, com uma média de $6,85( \pm 2,66)$ horas/dia, com turnos que variavam entre matutino/vespertino/noturno. Já $44,83 \%$ dos professores relataram trabalhar três turnos e, considerando que a pesquisa foi realizada com professores com carga horária de 20 a 40 horas semanais, pode-se sugerir que estes não possuem turno definido de trabalho, o que pode propiciar a realização de horas extras. Associado a isso, a instituição não adota o registro em cartão ponto pelos docentes, o que dificulta o acompanhamento das horas realizadas.

Os professores, acompanhados por Servilha e Pereira ${ }^{12}$, evidenciaram que a jornada de trabalho semanal compreendeu de 6 a 38 horas-aula, com média de 24 horas semanais. Em relação ao número de horas de trabalho diário, este variou de 2 a 16 horas-aula, sendo a faixa mais frequente de 6 horas. Os achados de Lima e Lima-Filho ${ }^{11}$ destacaram que maioria dos professores de uma IES Federal de Mato Grosso do Sul encontrava-se com excesso de carga horária, ou seja, 70,4\% estavam com encargos acima de 8 horas-aula semanais.

Cabe destacar que realização de horas extras preocupa, pois a sobrecarga, conflito e ambiguidade de papel são ressaltados como possíveis estressores no trabalho ${ }^{11}$.

Nos dados quanto às condições de infraestrutura, os professores destacaram enquanto aspectos inadequados na sala de aula o calor, ruídos externos, ventilação e frio com um somatório de $74,66 \%$. Acrescenta-se ainda que a ausência de espaço para descanso/repouso e de sala individual de trabalho, local inadequado para projeção de material didático, inadequação das mesas e cadeiras e das salas de aulas também são aspectos que interferem no ambiente de trabalho do professor ${ }^{8}$.
Os fatores referentes ao ambiente de trabalho têm sido considerados como fatores de risco para causar dano físico ou mental ao trabalhador ${ }^{13}$. No estudo de Pereira (2006), 32,4\% dos docentes apontaram que ter um ambiente e condições adequadas para o desenvolvimento de suas atividades como docente é muito importante para se manter saudável ${ }^{14}$.

As fontes importantes de tensão no trabalho referem-se às condições ambientais desfavoráveis, representadas por fatores como excesso de calor, ruídos e vibrações, que causam desconforto, aumentam o risco de acidentes e podem provocar danos significativos à saúde. 0 autor ressalta, no entanto, que um planejamento adequado de iluminação e de cores contribui para a melhoria da produtividade, aumento da satisfação no trabalho e redução da fadiga e de acidentes ${ }^{13}$.

Em relação à interferência do trabalho no dia a dia dos professores, estes relataram que o desempenho mental e físico estava comprometido, perfazendo um total de $55 \%$, no qual se pode hipotetizar que estes estão correndo risco de sofrer esgotamento mental e físico, pelo acúmulo de tarefas, elevado número de horas em sala de aula e falta de valorização.

Algumas são as causas de sofrimento físico e mental dos professores que acabam por desestimular o exercício da profissão, entre elas estão as turmas com muitos alunos, pressão dos horários, salário abaixo do nível de exigência de responsabilidade, falta de estabilidade no emprego, falta de promoção e expectativas, intensidade do trabalho, falta de reconhecimento social, falta de mão de obra que acaba sobrecarregando o professor em suas atividades, gerando exaustão física e e mocional, infraestrutura inadequada causadora de problemas de saúde graves, como lombalgias e Distúrbios Osteomusculares relacionados ao trabalho, falta de tempo para exercícios físicos e alimentação inadequada dentro e fora da instituição, devido ao excesso de trabalho ininterrupto ${ }^{15,16}$

Esses fatores de sobrecarga trazem como consequências o estresse, a queda da qualidade da aula ministrada, a impossibilidade de se aperfeiçoar constantemente, a falta de tempo e a desestimulação para preparar e refletir criticamente sobre sua prática pedagógica. Os docentes sentem 
o desgaste físico e/ou mental de longas jornadas de trabalho, necessárias para fazer diante da baixa remuneração e para manter um padrão de vida razoável ${ }^{17}$

Em relação aos aspectos que desestimulam o professor em sua carreira, $28,43 \%$ relataram que a carga horária elevada é o principal fator, seguido da desvalorização profissional, com 21,57\%, e $14 \%$ afirmaram que não têm aspectos que os desestimulem.

Pelos dados obtidos em relação à percepção de saúde, 58,62\% relataram que a saúde continua a mesma de um ano atrás; $20,69 \%$ relataram que a saúde está um pouco pior do que um ano atrás. Já $70 \%$ dos professores relataram ter alguma dor nas últimas quatro semanas, e destes $66,60 \%$ afirmaram que esta interferiu no trabalho. Percebe-se que o professor consegue ter a percepção das relações estabelecidas entre a saúde e trabalho, bem como o quanto o seu trabalho interfere na mesma. Silvany Neto et al. ${ }^{18}$ identificaram em seu estudo que $32,5 \%$ dos 573 professores pesquisados referiram ter tido problemas de saúde 15 dias antes da aplicação da pesquisa. As queixas mais frequentes eram em relação ao uso contínuo da voz, a algias na coluna vertebral, problemas psicossociais, cansaço e nervosismo. 0 estudo também relata que os problemas de saúde dos professores têm aumentado nos últimos anos.

Pode-se imaginar que o professor está trabaIhando muitas vezes sob pressão, o que interfere intimamente no desenvolvimento de suas atividades. Embora a maioria dos professores não tenha refletido sobre sua saúde, muitos afirmam que o exercício da profissão docente é composto por fatores importantes que comprometem sua saúde física e mental, causando-Ihes sofrimento e desgastes que desencadeiam doenças somáticas e psíquicas ou psicossomáticas, levando ao afastamento do posto de trabalho ${ }^{18}$.

Pesquisa de Delcor et al. ${ }^{16}$ evidenciou que o percentual de professores com diagnósticos médicos de saúde desde que começaram a trabalhar foi elevado. Em ambos os estudos é possível, mais uma vez, comprovar que a profissão do professor apresenta fatores de risco para a saúde, devido sua carga horária diária de trabalho, sobrecarga de atividades, condições físicas inadequadas para o exercício da profissão, pouco tempo para o descanso nos intervalos entre as aulas, além do trabaIho extraclasse desenvolvido em seus lares, o que minimiza o convívio familiar e social.

Vários fatores interferem na vida do professor, sejam de origem acadêmica, seja profissional e/ou familiar, estes que muitas vezes o impede de ter um estímulo para continuar seu ofício. Ao mesmo tempo, os professores buscam sua valorização na questão da profissionalização e estudo continuado. Mas é necessário e importante refletir sobre novas formas de exercer a função, sem que ela traga sofrimento e, em parceria com a IES, buscar novos caminhos para que estes fatores possam ser amenizados.

\section{Conclusão}

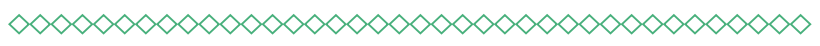

Conclui-se que a amostra foi homogênea quanto ao sexo, com faixa etária de 35 a 52 anos (72,42\%) e com boa qualificação, sendo que $93,10 \%$ eram doutores ou mestres. 0 tempo de profissão enquanto professor universitário teve uma média de $12,35( \pm 6,48)$ anos. Quanto ao tempo de trabaIho na IES a média foi de $10,86( \pm 5,60)$ anos.

Quanto aos turnos de trabalho predominou 0 grupo que trabalhava nos três turnos matutino/ vespertino/noturno (44,83\%), realizando uma média de $6,85( \pm 2,66)$ horas diárias e, $50,57 \%$ da amostra afirmaram realizar horas extras mensais, em uma média de $33( \pm 21,89)$. Quanto aos aspectos físicos da sala de aula citados pelos professores como mais inadequados, em primeiro lugar ficou o calor (31,51\%), seguido dos ruídos externos (23,29\%) e ventilação $(10,27 \%)$.

Em relação à interferência do trabalho no dia a dia, os professores destacaram que a rotina de trabalho estava interferindo no seu desempenho físico $(28,33 \%)$, seguido do desempenho mental $(26,67 \%)$ e o relacionamento com os filhos $(11,67 \%)$. Quanto aos aspectos que desestimulavam estes no trabalho, observou-se que a carga horária de trabalho elevada $(28,43 \%)$ foi a mais relatada, seguida da indisciplina dos acadêmicos $(17,65 \%)$ e desvalorização profissional $(21,57 \%)$. 
Já em relação ao sintoma dor, $70 \%$ dos professores relataram ter sentido alguma dor e, destes, $13,80 \%$ afirmaram que estas eram de intensidade moderada a grave, assim como $66,60 \%$ afirmaram que a dor interferiu na realização das tarefas vinculadas ao trabalho. Quanto à interferência da saúde física e emocional no trabalho, 32,18\% relataram que estas variáveis interferiram bastante na realização do trabalho; $26,44 \%$ relataram que interferiu moderadamente e $25,29 \%$ ligeiramente, somando um percentual de $83,91 \%$ dos professores que afirmaram ter interferência das condições de saúde na capacidade de trabalhar.

0 presente estudo confirmou que os professores se encontram constantemente expostos a fatores de risco, como dor, jornadas de trabalho exaustivas, turno de trabalho sem definição, realização de horas extras, sobrecarga mental e física e desestímulo pela função que se agregados a más condições de infraestrutura podem levar os professores ao adoecimento.

Ressalta-se a importância da realização de mais pesquisas, para comparar as diversas realidades e conhecer com mais detalhes as condições de saúde e trabalho dos professores universitários, bem como sobre o que pode ser planejado e modificado para amenizar e ou solucionar os problemas mais importantes.

\section{Referências}

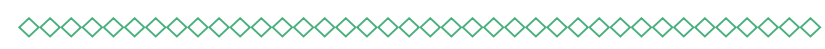

\section{Silva NEM, Santos DF, Freitas CES, Araújo TM,} Sena IP. Trabalho docente e saúde em uma instituição de ensino superior da Bahia. VI Seminário da Redestrado - Regulação Educacional e Trabalho Docente. 2006 Nov 06-07; Rio de Janeiro: UERJ, 2006.

2. Gomez CM, Costa SMF. A construção do campo da saúde do trabalhador: percurso e dilemas. Cad. Saúde Pública. 1997;13(2):21-32.

\section{Barbosa MSA, Santos RM, Trezza MCSF. A} vida do trabalhador antes e após a Lesão por Esforço Repetitivo (LER) e Doença Osteomuscular Relacionada ao Trabalho (DORT). Rev. Enferm. 2008;60(5):491-6.
4. Sato L. Prevenção de agravos à saúde do trabalhador: replanejando o trabalho através das negociações cotidianas. Cad. Saúde Pública. 2002;18(5):1147-57.

\section{Rizzardi DGF, Spessato MB. Autoridade} ou autiritarismo na prática docente: alguns pontos para reflexão. Revista Pedagógica. 2002;4(9):99-106.

6. Gasparini SM, Barreto SM, Assunção AA. 0 professor, as condições de trabalho e os efeitos sobre sua saúde. Revista Educação e Saúde. 2005;31(2):189-99.

7. Gomez CM, Lacaz FAC. Saúde do trabalhador: novas-velhas questões. Ciênc. saúde coletiva. 2005; 10(4):797-807.

8. Araújo TMD, Sena IPD, Viana MA, Araújo EM. Mal-estar docente. Avaliação de condições de trabalho e saúde em uma instituição de Ensino Superior. Rev. Baiana de Saúde Pública. 2005;29(1):6-21.

9. Matos EMB. Incidentes críticos do absenteísmo em situações de trabalho Industrial [tese]. Florianópolis: Universidade Federal de Santa Catarina; 2003.

10. Taube OLS. Análise da incidência de distúrbios musculoesqueléticos no trabalho do bibliotecário. Considerações ergonômicas com enfoque preventivo de LER/DORT [tese]. Florianópolis: Universidade Federal de Santa Catarina; 2002.

11. Lima MFEM, Lima-Filho DO. Condições de trabalho e saúde do/a professor/a universitário/a. Ciências e Cognição. 2009;14(3):62-82.

12. Servilha EAM, Pereira PM. Condições de trabalho, saúde e voz em professores universitários. Cienc. Med. 2008;17(1):21-31.

13. Martinez, MC. As relações entre a satisfação com aspectos psicossociais no trabalho e a saúde do trabalhador [dissertação]. São Paulo: Universidade de São Paulo, Programa de PósGraduação em Psicologia; 2002.

14. Pereira OAV. Qualidade de vida no trabalho de docentes universitários de uma instituição 
pública e outra privada do leste de Minas Gerais [dissertação]. Caratinga: Centro Universitário de Caratinga; 2006.

15. Potrich N, Nichel FMM. "Eu não sou nesta vida só professora": A organização do trabalho e o sofrimento dos educadores. Revista Pedagógica. 2005; 14:41-55.

16. Delcor NS, Araújo TM, Barbalho L. Condições de trabalho e saúde dos professores da rede particular de ensino de Vitória da Conquista, Bahia, Brasil. Cad. Saúde Pública. 2004;20(1):187-96.
17. Silva GLFS, Rosso AJ. As condições do trabalho docente dos professores das escolas públicas de Ponta Grossa - PR. In: VII Congresso Nacional de Educação da PUCPR - EDUCERE e no III Congresso Ibero-Americano sobre Violências nas Escolas CIAVE. 2008, Curitiba. Formação de 1: 495-536.

18. Silvany Neto AM, Araújo TMD, Dultra FR, Azi GR, Alves RL, Kavalkievick C, Reis EJ. Condições de Trabalho e Saúde dos Professores da Rede Particular de Ensino de Salvador. Rev. Baiana de Saúde Pública. 2000;24(1):42-56.

\section{Anexos}

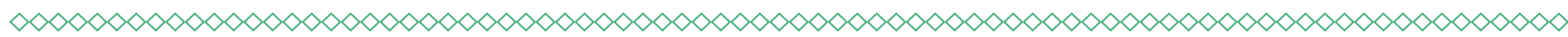

Tabela 1 - Perfil de Professores Universitários em uma IES em SC/2010

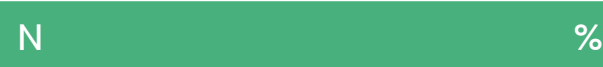

Gênero

\begin{tabular}{lcc}
\hline Feminino & 45 & 51,72 \\
Masculino & 42 & 48,28 \\
\hline Idade & 16 & 18,39 \\
\hline $29-34$ & 18 & 20,69 \\
$35-40$ & 23 & 26,44 \\
$41-46$ & 22 & 25,29 \\
$47-52$ & 5 & 5,75 \\
$53-58$ & 2 & 2,30 \\
$59-63$ & 1 & 1,15 \\
Acima de 64 & & 75,86 \\
\hline Titulação & 66 & 17,24 \\
\hline Mestre & 15 & 6,90 \\
Doutor & 06 & 100 \\
\hline Especialista & 87 & \\
\hline Total & & \\
\hline
\end{tabular}

Fonte: elaboração dos autores. 
Tabela 2 - Características do trabalho de professores em uma IES em SC/2010

\begin{tabular}{lcc} 
& $N$ & Média (DP) \\
Tempo de profissão & 87 & $12,35( \pm 6,48)$ \\
Tempo de atuação na IES & 87 & $10,86( \pm 5,60)$ \\
Horas de trabalho/dia & 87 & $6,85( \pm 2,66)$ \\
Horas extras/mês & 30 & $33( \pm 21,89)$ \\
\hline
\end{tabular}

Fonte: elaboração dos autores.

Tabela 3 - Aspectos físicos e desestimulantes do trabalho como professor em uma IES em SC/2010

\begin{tabular}{|c|c|c|}
\hline & $\mathrm{N}$ & $\%$ \\
\hline \multicolumn{3}{|c|}{ Aspectos Físicos da sala inadequados } \\
\hline Frio & 14 & 9,59 \\
\hline Calor & 46 & 31,51 \\
\hline Umidade & 1 & 0,00 \\
\hline Luminosidade & 4 & 2,74 \\
\hline Ventilação & 15 & 10,27 \\
\hline Altura do quadro & 7 & 4,79 \\
\hline Ruídos externos & 34 & 23,29 \\
\hline Carteira e cadeira inadequada & 7 & 4,79 \\
\hline $\begin{array}{l}\text { Elevado número de alunos } \\
\text { por sala }\end{array}$ & 7 & 4,79 \\
\hline Nenhum & 7 & 4,79 \\
\hline $\mathrm{NR}^{*}$ & 4 & 2,74 \\
\hline Total & 146 & 100 \\
\hline \multicolumn{3}{|c|}{ Aspectos que desestimulam o professor } \\
\hline $\begin{array}{l}\text { Carga horária de trabalho } \\
\text { elevada }\end{array}$ & 29 & 28,43 \\
\hline Indisciplina dos acadêmicos & 18 & 17,65 \\
\hline Desvalorização profissional & 22 & 21,57 \\
\hline Baixa remuneração & 8 & 7,84 \\
\hline Nenhum & 15 & 14,71 \\
\hline $\mathrm{NR}^{*}$ & 10 & 9,80 \\
\hline Total & 102 & 100 \\
\hline
\end{tabular}

NR* Não resposta.

Fonte: elaboração dos autores.

(clique para voltar ao texto) 
Tabela 4 - Percepção da saúde e dor de professores em uma IES em SC/2010

Percepção de Saúde

Muito melhor que um ano atrás 5

Pouco melhor que um ano atrás

12

13,79

Quase a mesma de um ano atrás

51

58,62

Pouco pior que um ano atrás

18

20,69

Muito pior que um ano atrás

1

1,15

Presença de dor

Nenhuma

26

29,90

Muito leve

24

27,60

Leve

25

28,70

Moderada

10

11,50

Grave

2

2,30

Interferência da dor no trabalho

\begin{tabular}{lcc}
\hline De maneira alguma & 29 & 33,30 \\
Um pouco & 30 & 34,50 \\
Moderadamente & 23 & 26,40 \\
Bastante & 4 & 4,60 \\
Extremamente & 1 & 1,10 \\
\hline Total & 87 & 100 \\
\hline
\end{tabular}

Fonte: elaboração dos autores.

(clique para voltar ao texto) 
Tabela 5 - Interferências do trabalho e da saúde na vida de professores em uma IES em SC/2010

\begin{tabular}{lcc} 
& $N$ & $\%$ \\
Interferência do trabalho no dia a dia & 32 & 26,67 \\
\hline Desempenho mental & 34 & 28,33 \\
Desempenho físico & 14 & 11,67 \\
Relacionamento com os filhos & 9 & 7,50 \\
Relacionamento com o & 5 & 4,17 \\
companheiro/a & 15 & 12,50 \\
Relacionamento sexual & 11 & 9,16 \\
Não afeta & 120 & 100 \\
NR* & 9 & 10,34 \\
\hline Total & 22 & 25,29 \\
\hline Interferência da saúde física e emocional no trabalho & 26,44 \\
\hline De forma nenhuma & 23 & 32,18 \\
Ligeiramente & 28 & 5,75 \\
Moderadamente & 5 & \\
Bastante & & \\
Extremamente & 9 &
\end{tabular}

